\title{
RANCANG BANGUN SOLAR ELECTRIC SPRAYER HEMAT ENERGI MENGGUNAKAN METODE FUZZY EXPERT SYSTEM
}

\author{
Totok Dewantoro ${ }^{1}$, Gezaq Abror ${ }^{2}$, Gilang Vigo ${ }^{3}$ \\ Teknologi Listrik, Fakultas Vokasi \\ Universitas 17 Agustus 1945 Surabaya, Indonesia \\ e-mail : 1totok.dewantoro@untag-sby.ac.id,2gezaq@untag-sby.ac.id,3gilang.vigo@gmail.com \\ Diterima: 24 Oktober 2019. Disetujui : 26 Nopember 2019. Dipublikasikan : 31 Desember 2019 \\ (C)2019 -TESJ Fakultas Teknik Universitas Maarif Hasyim Latif. Ini adalah artikel dengan \\ akses terbuka di bawah lisensi CC BY 4.0 (https://creativecommons.org/licenses/by/4.0/)
}

\begin{abstract}
ABSTRAK
Pada penelitian ini akan dirancang sebuah solar electric sprayer (SES) yang hemat energi. Rancangan ini terdiri dari solar panel (PV), rangkaian maximum power point tracking (MPPT), dan sebuah konverter. Untuk memaksimalkan power dari solar panel, rancangan ini dilengkapi dengan MPPT yang mampu bekerja pada kondisi terbayang-bayang sebagian (partial shaded) apabila tempat yang digunakan tidak memungkinkan untuk memperoleh radiasi matahari yang sempurna. Algoritma yang digunakan pada pembuatan MPPT ini menggunakan fuzzy expert system (FES). Dari hasil pengujian didapatkan daya optimal PV hanya sekitar 75\% dengan effisiensi konverter $80 \%$ hingga $89 \%$ tanpa terjadi saturasi, namun terdapat penurunan effisiensi sekitar $42 \%$ apabila dutycycle dibawah $40 \%$. Dengan demikian prototype mesin semprot listrik bertenaga surya sebagai pengganti mesin semprot manual yang sudah tersedia dapat diterapkan.
\end{abstract}

Kata kunci: fuzzy expert system, mppt, solar electric sprayer

\section{PENDAHULUAN}

Jakarta, CNN Indonesia --Berdasarkan data yang diperoleh dari BPS (Badan Pusat Statistik) Tahun 2018, pekerja di bidang pertanian tercatat sejumlah 35,7 juta jiwa atau 28,79\% dari jumlah penduduk bekerja 124,01 juta jiwa. Sementara di tahun 2017, jumlah pekerja bidang pertanian di angka 35,9 juta jiwa atau 29,68 persen dari jumlah penduduk bekerja 121,02 juta orang.

Sektor pertanian inilah yang merupakan penunjang kebutuhan hidup sebagian besar masyarakat Indonesia. Adanya hal tersebut, maka sektor dibidang pertanian memiliki peranan yang penting, karena sebagai sumber penghasil pangan bagi penduduk yang tiap tahun jumlahnya selalu bertambah. Akan tetapi, ada beberapa kendala yang sering dialami oleh para petani. Salah satu diantaranya adalah saat proses penyemprotan yang masih dilakukan secara konvensional yaitu menggunakan sistem mekanik maupun hybrid (elektrik dan mekanik). Kedua sistem tersebut masih memiliki kekurangan yaitu butuh tenaga manusia sebagai penggeraknya maupun masih adanya kemungkinan kehabisan daya baterai.

Pada penelitian ini, diusulkan sebuah prototype solar electric sprayer system sebagai pengganti sistem manual pada electric sprayer saat ini. Yang memungkinkan perangkat masih tetap dapat dipergunakan saat baterai utama habis. Sehingga proses penyemprotan masih tetap dapat dilakukan. Rancangan ini terdiri dari solar panel, rangkaian maximum power point tracking (MPPT), konverter dan sprayer. Metode yang dipergunakan untuk mengoptimasi kinerja MMPT adalah menggunakan fuzzy expert system (FES).

\section{METODE PENELITIAN}

Pada penelitian ini menggunakan tahapan sebagaimana pada Gambar 1.

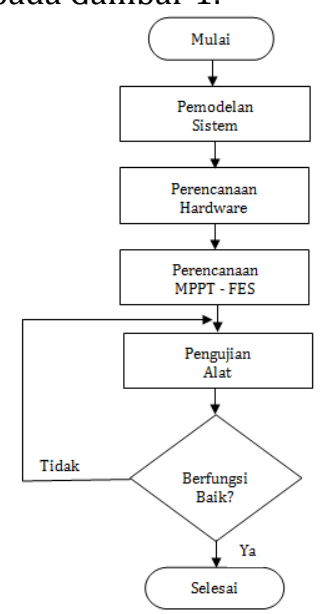

Gambar 1. Flowchart penelitian 


\section{Pemodelan sistem}

Model sistem yang diusulkan pada penelitian ini dapat dilihat seperti Gambar 2.

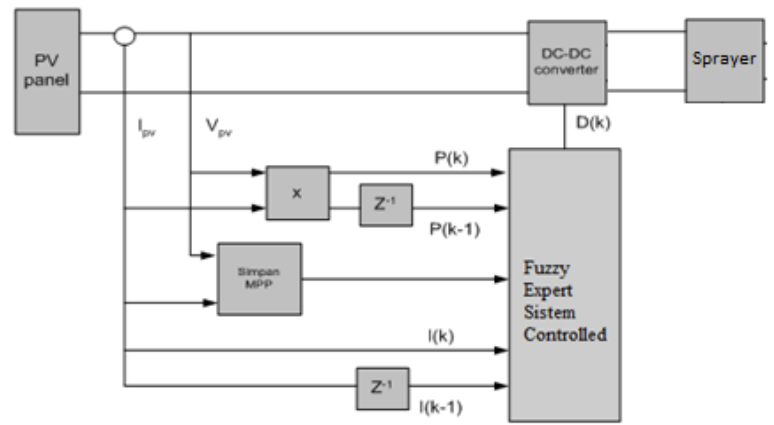

Gambar 2. Konfigurasi sistem MPPT berbasis fuzzy expert sistem

\section{Perencanaan perangkat keras}

Pembuatan perangkat keras meliputi pembuatan rangkaian dummy load, rangkaian DCDC konverter, serta rangkaian pendukung (sensorsensor, rangkaian driver dan interface untuk arduino).

\section{DC - DC Konverter}

Desain DC-DC konverter yang akan digunakan adalah menggunakan konverter buck seperti Gambar 3.

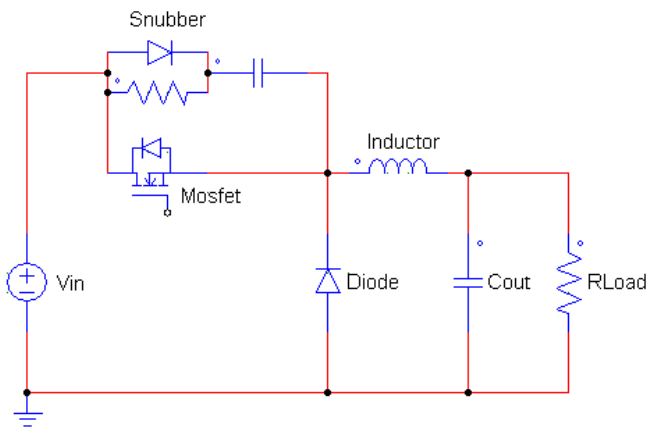

Gambar 3. Rangkaian konverter buck

Pada Gambar 3 rangkaian konverter yang digunakan, masih diperlukan pencarian besaran nilai-nilai serta rating dari masing masing komponen yang mengacu pada parameter Tabel 1 .

Tabel 1. Parameter konverter buck prototipe SES

\begin{tabular}{c|l|c}
\hline No & \multicolumn{1}{|c|}{ Parameter } & Nilai \\
\hline 1 & $P_{\text {Max }}$ & 15,66 watt \\
\hline 2 & $V_{\text {in }}$ & 15 volt \\
\hline 3 & $V_{\text {Out }}$ & 12 volt \\
\hline 4 & Iin $^{\prime}$ & 1,04 ampere \\
\hline 5 & Duty cycle & $80 \%$ \\
\hline 6 & Frekuensi switching & $31.250 \mathrm{~Hz}$ \\
\hline 7 & BMax & 0,25 tesla \\
\hline
\end{tabular}

Untuk perhitungan parameter-parameter digunakan persamaan berikut:

$$
\begin{gathered}
D=\frac{V_{\text {in }}}{V_{\text {out }}} \\
I_{L}=I_{\text {out }}=\left[\frac{V_{\text {out }}}{(R)}\right] \\
\Delta I_{L}=0,1 \times I_{L} \\
L=\left(\frac{1}{f}\right) x\left[V_{\text {in }}-V_{\text {out }}\right] x\left(\frac{V_{\text {out }}+V_{F}}{V_{\text {in }}+V_{F}}\right) \times\left(\frac{1}{\Delta I_{L}}\right) \\
I_{\text {Lmax }}=I_{L}+\frac{\Delta I_{L}}{2} \\
n=\frac{L . I_{\text {Lmax }}}{B_{\text {Max }} A_{o}} \times 10^{4} \\
C=\frac{\Delta Q}{\Delta V_{o}} \\
C_{\text {snubber }}=\frac{I_{\text {on }} x t_{\text {fall }}}{2 x V_{\text {off }}} \\
R_{\text {snubber }}<\frac{D T}{2 x C_{\text {snubber }}}
\end{gathered}
$$

Keterangan:

D : Dutty Cycle

IL : Arus induktor

L : Induktor

C : Kapasitor

$\mathrm{R} \quad$ : Resistor

$\mathrm{n} \quad$ : Jumlah lilitan

$V_{\text {in }} \quad:$ Tegangan input

$V_{\text {out }}$ : Tegangan output

f : Frekuensi

ILmax : Arus maks induktor

\section{Desain algoritma MPPT dengan fuzzy expert sistem}

Input sistem terdiri dari 2 variabel yaitu tegangan dan arus.. Membership function untuk input baik itu tegangan dan arus yaitu sangat rendah (SR), rendah (R), sedang (S), tinggi (T) dan sangat tinggi (ST). Sedangkan variabel output adalah dutycycle yang dikeluarkan oleh MPPT. Membership function output yaitu mulai sangat kecil (SK), kecil (K), sedang (S), besar (B) dan sangat besar (SB). Blok diagram untuk proses fuzzy dapat dilihat di Gambar 4.

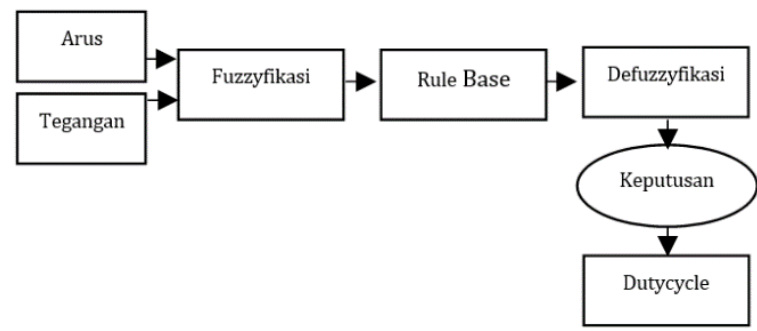

Gambar 4. Blok diagram proses fuzzy

\section{Fuzzyfikasi}

Pada tahap fuzzyfikasi, data input yang tajam diubah menjadi data input fuzzy, kemudian dibuat fungsi keanggotaan input yaitu tegangan dan arus yang ditunjukkan Gambar 5 dan Gambar 6. 


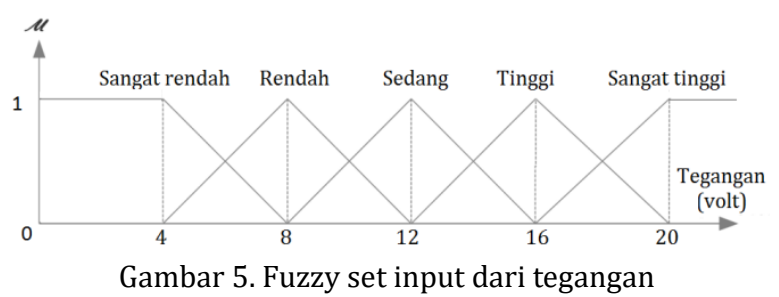

Untuk membership function input tegangan kategori sangat rendah (0-8), rendah (4-12), sedang (8-16), tinggi (12-20), sangat tinggi (16 keatas).

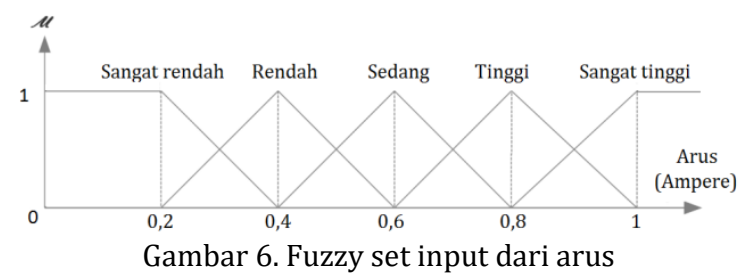

Untuk membership function input arus kategori sangat rendah $(0-0,2)$, rendah $(0,2-0,6)$, sedang $(0,4-0,8)$, tinggi $(0,6-1,0)$, sangat tinggi $(0,8$ keatas).

\section{Fuzzy rule base}

Sistem dibuat menjadi 25 rule, seperti pada tabel 2. Rule-rule yang digunakan merupakan hasil laboratorium dan pemikiran para ahli.

\begin{tabular}{c|c|c|c|c|c}
\multicolumn{6}{c}{ Tabel 2. Rule base } \\
\hline V & SR & R & S & T & ST \\
\hline SR & SK & SK & SK & SK & SK \\
\hline R & SK & K & K & K & K \\
\hline S & SK & K & S & S & S \\
\hline T & SK & K & S & B & B \\
\hline ST & SK & K & S & B & SB \\
\hline
\end{tabular}

\section{Defuzzyfikasi}

Pada tahap defuzzyfikasi, data fuzzy output dikonversi menjadi crisp output data. Membership function output untuk dutycycle dikategorikan menjadi: sangat kecil (0-40), kecil (20-60), sedang (40-80), besar (60-80), sangat besar (80 keatas) seperti terlihat pada Gambar 7.

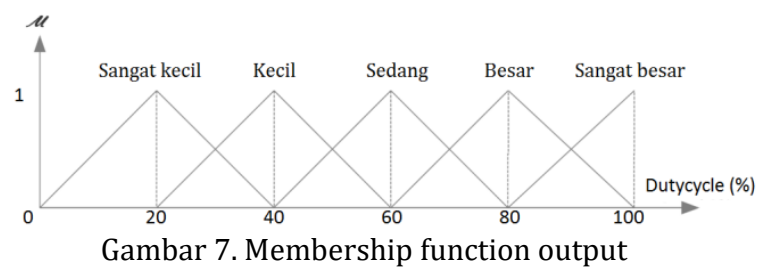

Untuk menghitung nilai crisp output fuzzy logic pada tahapan defuzzyfikasi, maka digunakan metode Centre of Gravity (COG). Rumus COG dapat dijabarkan pada persamaan 10.

$$
C O G=\sum_{i=1}^{n} \frac{Z_{i} \mu\left(Z_{i}\right)}{\mu\left(Z_{i}\right)}
$$

$$
\begin{array}{ll}
\mathrm{Z}_{\mathrm{i}} & : \text { Fuzzy output } \\
\mu\left(\mathrm{Z}_{\mathrm{i}}\right) & : \text { Membership function output }
\end{array}
$$

\section{Pengujian Alat}

Pengujian alat pada penelitian ini meliputi pengujian karakteristik Photovoltaic (PV), pengujian metode MPPT pada konverter dan pengujian fungsi alat secara keseluruhan setelah semua perangkat terintegrasi.

\section{HASIL DAN PEMBAHASAN}

\section{Karakteristik photovoltaic}

Pengujian karakteristik Photovoltaic (PV) diperlukan sebagai acuan perancangan topologi konverter yang akan digunakan pada penelitian ini. Pengujian ini meliputi pengukuran tegangan open circuit $\left(\mathrm{V}_{\mathrm{OC}}\right)$, pengukuran arus short circuit ( $\mathrm{I}_{\mathrm{SC}}$ ) dan pengukuran tegangan optimum ( $\left.\mathrm{V}_{\mathrm{MPP}}\right)$. Gambar rangkaian pengujian karakteristik photovoltaic dapat dilihat seperti Gambar 8.

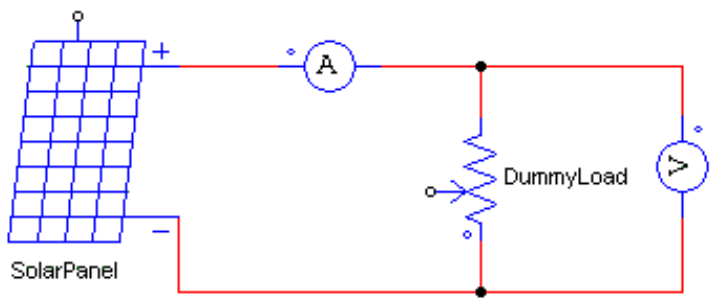

Gambar 8. Rangkaian pengujian karakteristik photovoltaic

Data karakteristik PV dapat dilihat pada Tabel 3, data diambil pada bulan Agustus 2019 pukul 09.06 WIB dengan kondisi cuaca cerah dan dalam posisi ortogonal terhadap bidang permukaan PV.

Tabel 3. Data pengujian PV tanpa bayangan

\begin{tabular}{c|r|r|r}
\hline Beban & $\begin{array}{c}\text { Tegangan } \\
\text { (volt) }\end{array}$ & $\begin{array}{c}\text { Arus } \\
\text { (ampere) }\end{array}$ & $\begin{array}{c}\text { Daya } \\
\text { (watt) }\end{array}$ \\
\hline Open circuit & 20,06 & 0 & 0 \\
\hline & 15,02 & 1,04 & 15,66 \\
\hline & 10,10 & 0,59 & 6,00 \\
\hline & 4,90 & 1,09 & 5,34 \\
\hline Short circuit & 0,00 & 1,13 & 0,00 \\
\hline
\end{tabular}

\section{Karakteristik partially shaded}

Pengujian dibuat seolah olah tertutup 25\% dengan cara menutupi sebagian permukaan PV seperti Gambar 9. 


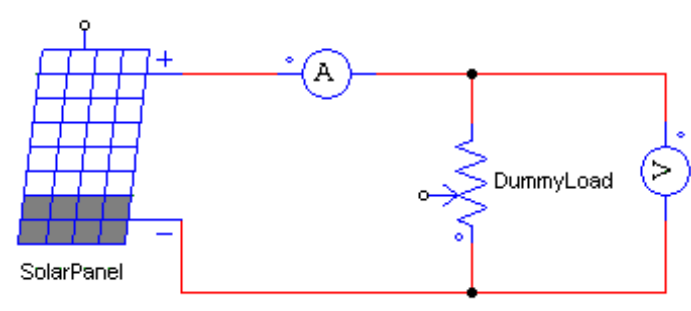

Gambar 9. Rangkaian pengujian karakteristik photovoltaic partially shaded

Sedangkan data pengujian saat kondisi terbayang sebagian atau partially shaded ditunjukkan pada Tabel 4.

Tabel 4. Data karakteristik PV saat partially shaded

\begin{tabular}{c|r|r|r}
\hline Beban & $\begin{array}{c}\text { Tegangan } \\
\text { (volt) }\end{array}$ & $\begin{array}{c}\text { Arus } \\
\text { (ampere) }\end{array}$ & $\begin{array}{c}\text { Daya } \\
\text { (watt) }\end{array}$ \\
\hline Open circuit & 20,06 & 0 & 0 \\
\hline & 14,90 & 0,35 & 6,56 \\
\hline & 10,10 & 0,63 & 6,36 \\
\hline & 4,85 & 0,66 & 3,23 \\
\hline Short circuit & 0,00 & 0,67 & 0,00 \\
\hline
\end{tabular}

\section{Pengujian DC - DC koverter}

Pengujian ini bertujuan untuk mengetahui karakteristik dari konverter yang telah dibuat apakah sudah sesuai dengan parameter acuan, Hasil uji disajikan pada tabel 5.

Tabel 5. Pengujian buck konverter

\begin{tabular}{|c|c|c|c|c|c|c|c|}
\hline \multirow{2}{*}{$\begin{array}{l}\text { Duty } \\
\text { cycle }\end{array}$} & \multicolumn{3}{|c|}{ Input } & \multicolumn{3}{|c|}{ Output } & \multirow{2}{*}{$\begin{array}{l}\text { Efisi } \\
\text { ensi }\end{array}$} \\
\hline & Volt & Arus & Daya & Volt & Arus & Daya & \\
\hline 10 & 15 & 0,02 & 0,31 & 1,3 & 0,13 & 0,17 & 0,54 \\
\hline 20 & 15 & 0,07 & 1,08 & 2,4 & 0,32 & 0,76 & 0,7 \\
\hline 30 & 15 & 0,15 & 2,32 & 3,5 & 0,5 & 1,76 & 0,76 \\
\hline 40 & 15 & 0,27 & 4,02 & 4,7 & 0,71 & 3,34 & 0,83 \\
\hline 50 & 15 & 0,41 & 6,18 & 6,1 & 0,86 & 5,25 & 0,85 \\
\hline 60 & 15 & 0,59 & 8,8 & 7,3 & 1,06 & 7,74 & 0,88 \\
\hline 70 & 15 & 0,79 & 11,89 & 8,3 & 1,27 & 10,58 & 0,89 \\
\hline 80 & 15 & 1,04 & 15,6 & 9,5 & 1,46 & 13,88 & 0,89 \\
\hline 90 & 15 & 1,21 & 18,15 & 10,7 & 1,51 & 16,15 & 0,89 \\
\hline
\end{tabular}

Dari tabel pengujian tersebut, diplot bentuk grafik peforma efesiensi dari konverter yang telah dibuat.

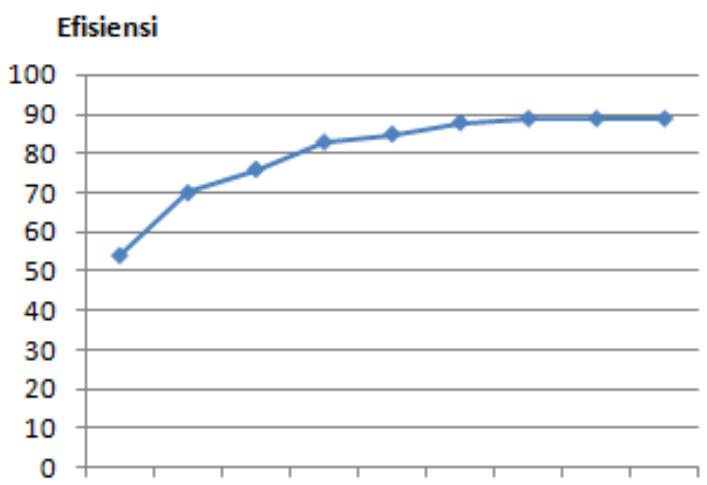

$10 \% 20 \% 30 \%$ 40\% 50\% 60\% 70\% 80\% $90 \%$

Gambar 10. Performa efisiensi konverter
Dari gambar performa efisiensi, koverter terlihat baik hingga dutycyle 90\%, dan tidak menunjukkan adanya saturasi saat dutcycle 10\% s.d 90\%. namun untuk dutycyle di bawah $40 \%$, ada penurunan effisiensi hingga $42 \%$.

\section{Pengujian Alat secara keseluruhan}

Hasil dari rancang bangun yang dibuat dapat dilihat pada Gambar 11. Pada gambar tersebut tidak terdapat sistem mekanik sama sekali, hal ini sesuai dengan target penelitian yaitu menggantikan sistem lama yang sudah ada (sistem mekanik) menjadi sistem solar/PV.

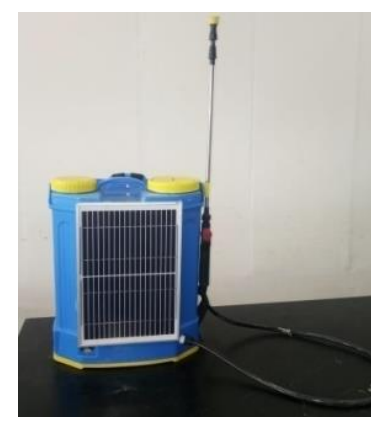

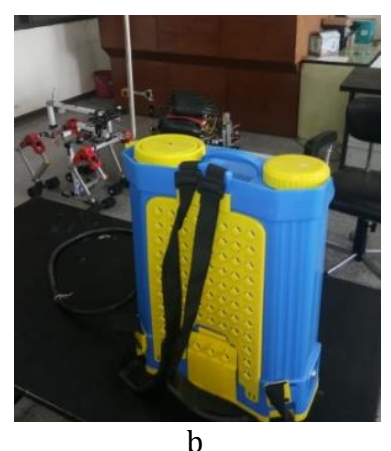

b
Gambar 11. Rancang bangun solar electric sprayer

Sedangkan data pengujian untuk mengetahui fungsi dan efektifitas dari solar electric sprayer yang dibuat, disajikan pada tabel 6 .

Tabel 6. Hasil pengujian SES dengan MPPT- FES

\begin{tabular}{c|c|c|c}
\hline $\begin{array}{c}\% \\
\text { PV terbayang }\end{array}$ & $\begin{array}{c}\text { Daya MPPT } \\
\text { (Watt) }\end{array}$ & $\begin{array}{c}\text { Daya tersedia } \\
\text { (Watt) }\end{array}$ & Efisiensi (\%) \\
\hline $0 \%$ & 15,46 & 15,66 & $98,71 \%$ \\
\hline $25 \%$ & 6,48 & 6,56 & $98,82 \%$ \\
\hline
\end{tabular}

Dari tabel hasil pengujian alat solar electric sprayer tersebut, terlihat bahwa fungsi dari MPPT yang diusulkan mampu mendekati nilai optimum MPPnya dengan effisiensi sekitar 98\%.

\section{PENUTUP}

Pembuatan rancang bangun solar electric sprayer hemat energi yang telah dibuat masih berupa prototipe sederhana yang terdiri dari solar panel, rangkaian MPPT dan sebuah DC konverter.

Dari hasil pengujian yang dilakukan terhadap solar panel / PV sebesar 20 watt peak, hanya didapatkan daya optimal sebesar $75 \%$, hal ini dikarenakan saat pengujian radiasi sinar matahari tidak diterima seluruhnya oleh PV. Sedangkan effisiensi konverter terlihat baik untuk dutycyle 40\%-90\%, dan tidak terjadi saturasi, namun untuk dutycyle $<40 \%$, ada penurunan effisiensi hingga 42\%. Untuk mengetahui tingkat efektifitas dari prototipe yang dibuat sebaiknya 
diperlukan pengembangan metode mppt selain fuzzy misalnya GA, PSO, FA dll dan menggunakan DC konverter yang lebih kompleks.

\section{UCAPAN TERIMA KASIH}

Terima kasih kami ucapkan kepada LPPM Untag Surabaya yang telah membiayai penelitian ini melalui hibah perguruan tinggi.

\section{DAFTAR PUSTAKA}

Abror, G., Widodo, R. T., \& Al Rasyid, M. U. H. (2018). Dynamic Sleep Scheduling on Air Pollution Levels Monitoring with Wireless Sensor Network. EMITTER International Journal of Engineering Technology, 5(2), 209-233.

Gilang, A. (2018). Jumlah Petani Berkurang, Tingkat Pengangguran Di Desa Naik. Retrieved from CNN Indonesia website: https://www.cnnindonesia.com/ekonomi/2 0181105141729-532-344096/jumlahpetani-berkurang-tingkat-pengangguran-di- desa-naik

Guo, S., Wu, C., Danner, M., Nobre, A., Aberle, A. G., \& Peters, M. (2015). Modelling of an integrated standalone streetlamp PV system. 2015 IEEE 42nd Photovoltaic Specialist Conference (PVSC), 1-5. IEEE.

Priananda, C. W. (2017). Desain Model Mppt Baru Pada Topologi PV Farm Berbasis Cluster Yang Tertutup Bayangan Sebagian. Institut Teknologi Sepuluh Nopember.

Shanliang, Y., Yuewen, F., Peng, Z., \& Kedi, H. (2013). Implementation of a rule-based expert system for application of weapon system of systems. Proceedings 2013 International Conference on Mechatronic Sciences, Electric Engineering and Computer (MEC), 2603-2606. IEEE.

Taheri, H., Salam, Z., \& Ishaque, K. (2010). A novel maximum power point tracking control of photovoltaic system under partial and rapidly fluctuating shadow conditions using differential evolution. 2010 IEEE Symposium on Industrial Electronics and Applications (ISIEA), 82-87. IEEE. 
T Dewantoro, dkk / Teknika : Engineering and Sains Journal, Vol. 3, No.2, Desember 2019, 83-88

Halaman ini sengaja dikosongkan 